với các triệu chứng lâm sàng dưới 1 giờ và không có nhồi máu não cấp tính trên CT scaner và nhất là trên MRI. Đột quị não là rối loạn thân kinh khu trú hoặc toàn thể của chức năng não do rối loạn chức năng mạch máu, kéo dài hơn 24 giờ hoặc dẫn đến tử vong. Trong nghiên cứu của chúng tôi thời lượng cơn AHRE trên 5,5 giờ làm tăng gấp đôi nguy cơ đột quị não, TIA của bệnh nhân nhóm nghiên cứu, kết quả này có ý nghĩa thống kê với $p<0,05$. Điều này cho thấy rằng thời lượng cơn AHRE càng dài nguy cơ đột quị não, TIA càng tăng.

\section{KẾT LUÂ̂N}

Trong nghiên cứu của chúng tôi, bệnh nhân rối loạn nhịp nhĩ nhanh bao gồm cơn AHRE, rung nhĩ thường không có biểu hiện triệu chứng trên lâm sàng. Đồng thời biến cố tắc mạch nguy cơ xảy ra ở thời lượng cơn AHRE trên 5,5 giờ với $\mathrm{CI}$ 95\% $(0,006-0,4), p<0,05$.

\section{TÀI LIÊU THAM KHẢO}

1. Camm A.J., Simantirakis E., Goette A. và cộng sự. (2017). Atrial high-rate episodes and stroke prevention. Europace, 19(2), 169-179.

2. Lu W.-D. và Chen J.-Y. (2021). Clinical Cardiology, 44(6), 871-879.

3. Kirchhof 'P., Benussi S., Kotecha D. và cộng sư. (2016). 2016 ESC Guidelines for the management of atrial fibrillation developed in collaboration with EACTS. European journal of cardio-thoracic surgery: official journal of the European Association for Cardio-thoracic Surgery, 50, e1-e88.

4. Lu W.-D. và Chen J.-Y. (2021). Atrial high-rate episodes and risk of major adverse cardiovascular events in patients with dual chamber permanent pacemakers: a retrospective study. Scientific Reports, 11(1), 5753.

5. Trương Văn Nhi,Trân Song Giang. (2017), Nghiên cứu tân suât rung nhĩ và nguy cơ tăc mach ở bệnh nhân mang máy tạo nhịp vĩnh viễn hai buồng. Luân văn thạc sĩ y học, Đai học y Hà Nội.

6. Hoàng Phương Nam (2019), Đặc điểm rối loan nhịp nhanh và nguy cơ tắc mạch ở bệnh nhẩn mang máy tạo nhịp vĩnh viến hai buồng., Luận văn thạc sĩ y học, Đại học y Hà Nội.

7. Lế Tiến Dũng, Trân Sơng Giang, Nguyễn Ngọc Quang (2014), Nghiên cứu đặc điểm rối loạn nhịp tim ở bệnh nhân có hội chứng suy nút xoang trước và sau cấy máy tạo nhịp vĩnh viến. Luận văn thạc sỹ Tim Mạch. Đại học y Hà Nội.

\title{
ĐÁNH GIÁ KIẾN THỨC VỀ THỜI KỲ HÂUU SẢN VÀ CHĂM SÓC HÂUU SẢN CỦA BÀ ME SINH TẠI KHOA SẢN BỆNH VIỆN VINMEC 2021
}

\author{
Hồ Hoàng Thu Phương ${ }^{1}$, Lưu Tuyết Minh², \\ Nguyễn Bích Hạnh ${ }^{1}$, Nguyễn Thị Hồng ${ }^{1}$, Vũ Thị Thu Thảo
}

\section{TÓM TẮT.}

Mục tiêu: Mô tả kiến thức về chăm sóc sức khỏe thời kỷ hậu sản sau sinh nằm tại khoa phụ sản - Bệnh viện Vinmec năm 2020 và một số yếu tố liên quan. Đối tượng và phương pháp nghiên cứu: Nghiên cứu mô tả cắt ngang trên 201 bà mẹ sinh thường tại khoa Phụ Sản Bệnh viện Vinmec năm 2020. Kết quả: Các bà mé có độ tuổi trung bình là $29,6 \pm 4,0$. Có $80,6 \%$ số bà mẹ có đạt kiến thức về chăm sóc sức khỏe thời kỳ hậu sản và có $97,1 \%$ số bà me đạt kiến thức chăm sóc sức khỏe trẻ sơ sinh. Nghiên cứu tìm thấy mỗi liên quan có ý nghĩa thống kê giữa mức độ hiểu biết và yếu tố nghề nghiệp của các bà mẹ và chưa tìm thấy mỗi liên quan với các yếu tố khác.

Tư khóa: Kiến thức, hậu sản, chăm sóc sau sinh.

\section{SUMMARY}

${ }^{1}$ Bệnh viện đa khoa quốc tế VinMec,

${ }^{2}$ Trường Đại học Y Hà Nội

Chịu trách nhiệm chính: Hồ Hoàng Thu Phương

Email: thuphuong.hmu@gmail.com

Ngày nhận bài: 6.5.2021

Ngày phản biện khoa học: 24.6.2021

Ngày duyệt bài: 8.7.2021

\section{KNOWLEDGE ON POSTNATAL CARE AMONG} POSTPARTUM MOTHERS IN VINMEC

\section{HOSPITAL: A CROSS-SECTIONAL STUDY}

Aims: To describe knowledge about health care in the postpartum period at the obstetrics and gynecology department of Vinmec Hospital in 2020 and some related factors. Subjects and methods: A cross-sectional descriptive study on 201 mothers giving birth vaginally at the Department of Obstetrics and Gynecology at Vinmec Hospital in 2020. Results: The average age of mothers was $29.6 \pm 4.0,80.6 \%$ of mothers had knowledge of postpartum health care and $97.1 \%$ of mothers. Gain knowledge of infant health care. The study found each statistically significant association between mothers' level of knowledge and occupational factors and did not find each associated with other factors.

Keywords: knowledge, postpartum, postpartum

\section{I. ĐẶT VẤN ĐỀ}

Sinh con là hành trình vượt cạn đầy thử thách, khó khăn với nhiều cung bậc cảm xúc của người mẹ. Hậu sản là khoảng thời gian 6 tuần lễ sau sinh. Trong khoảng thời gian này, các cơ 
quan trong cơ thể người mẹ, nhất là những cơ quan sinh dục sẽ dần dần trở về trạng thái bình thường như trước khi có thai, trừ tuyến vú vẫn tiếp tục phát triển để tiết sữa. Thời kỳ hậu sản được đánh dấu bằng những hiện tượng chính là sự thu hồi của tử cung, sự tiết sản dịch, sự lên sữa và tiết sữa, và những thay đổi tổng quát khác [1]. Đây là khoảng thời gian vô cùng nhạy cảm đối với các bà mẹ, nếu không có kiến thức và chăm sóc đầy đủ ở giai đoạn này có thể dẫn đến những hậu quả vô vùng đáng tiếc. Việt Nam đã có những tiến bộ ấn tượng trong công tác chăm sóc sức khỏe sinh sản và sức khỏe bà me trẻ em. Với tỷ lệ tử vong me giảm 4 lần và tỷ lẹ̉ tử vong trẻ em dưới 5 tuối giảm mạnh xuống còn một nửa trong những thập kỷ gần đây, chỉ số sức khỏe bà mẹ trẻ em của Việt Nam ưu việt hơn so với các quốc gia có mức thu nhập bình quân đầu người tương đương. Dù đã đạt được những tiến bộ như vậy, việc sinh con ở Việt Nam vẫn là một việc làm đầy rủi ro đối với nhiều phụ nữ và con cái của họ. Việc không được tiếp cận đầy đủ tới dịch vụ chăm sóc sức khỏe trong thời gian mang thai, sinh con và khi mới sinh chính là nguyên nhân gây ra 600 ca tử vong me và hơn 10.000 ca tử vong trẻ sơ sinh được ghi nhận ở Việt nam mỗi năm [2].

Tại khoa sản Bệnh viện VinMec hàng năm có khoảng $1.000 \mathrm{ca}$ sinh thường. Nhưng vần chưa có nghiên cứu nào về kiến thức thời kỳ hậu sản và chăm sóc hậu sản của bà mẹ. Vì vậy tôi đã làm nghiên cứu: "Đánh giá kiến thức về thời kỳ hậu sản và chăm sóc hậu sản của bà me sinh tại khoa sản Bệnh viện Vinmec năm 2021" nhằm đạt mục tiêu: Mô tả về thời kì hậu sản và chăm sóc hậu sản của bà me sau sinh nằm tại khoa phụ sản và một số yếu tố liên quan tại Bệnh viện Vinmec nằm 2021. Kết quả nghiên cứu nhă̆m mục đích nâng cao chất lượng chăm sóc và giáo dục sức khỏe bà me sau đẻ thường toàn diện, không chỉ dừng lại ở việc chăm sóc tại bệnh viện mà còn chăm sóc khi bà mẹ về nhà.

\section{II. ĐỐI TƯợNG VÀ PHƯƠNG PHÁP NGHIÊN CỨU}

2.1. Đối tượng nghiên cứu. Là những bà mẹ sau đẻ thường tại Khoa Phụ sản - Bệnh viện Vinmec từ 01/06/2020 đến 01/06/2021.

2.2. Thiết kế nghiên cứu: Mô tả cắt ngang

- Thời gian nghiên cứu: Từ tháng 6/2020 đến tháng 6/2021, thời gian thu thập số liệu: tháng $6 / 2020$.

- Địa điểm nghiên cứu: Nghiên cứu được tiến hành tại Khoa phụ sản-Bệnh viện Đa Khoa Vinmec.

2.3. Phương pháp chọn mấu và cỡ mẫu:
Sử dụng công thức tính cõ mẫu: ước tính một tỷ lệ trong quần thể.

$$
\mathrm{n}=Z_{1-\frac{\alpha}{2}}^{2} \frac{p(1-p)}{\varepsilon^{2}}
$$

Trong đó: - $\mathrm{n}$ là số bà mẹ đẻ thường tham gia nghiên cứu.

- Ước tính cõ̃ mẫu với $p=0,8$. Sử dụng $p$ là tỷ lệ bà mẹ có kiến thức đạt $80 \%$ dựa trên nghiên cứu của Vũ Đình Hùng ở bệnh viện Bạch Mai( 2016 )[3]

- Z: Hệ số tin cậy, giá trị Z2¹- a/ 2= 1,96 tương ứng với $a=0,05$

- $\varepsilon$ : Mức độ chính xác mong muốn $(\varepsilon=0,06)$

- Số mẫu qua tính toán là 171 người.

- Cộng thêm $10 \%$ sai số khi lấy thông tin.

- Qua tính toán: Cõ̃ mẫu NC sẽ là 188 người, tuy nhiên qua khảo sát thây có bà mẹ đủ điêu kiện tham gia nghiên cứu vì vậy chúng tôi lấy cỡ mấu là $n=201$.

2.4.Công cụ thu thập số liệu: Thông tin sẽ được thu thập theo bộ cẩu hỏi nghiên cứu.

2.5. Phương pháp thu thập số liệu: Chọn các đối tượng đủ tiêu chuẩn và đồng ý tham gia nghiên cứu, sau đó phỏng vấn các đối tượng theo bộ câu hỏi nghiên cứu.

2.6.Xử lý số liệu: Số liệu sau khi thu thập sẽ được làm sạch và nhập vào máy tính bằng phần mềm Epidata 3.1. Phân tích số liệu được thực hiện bằng phần mềm SPSS 20.

2.7.Đạo đức nghiên cứu: Đối tượng nghiên cứu được giải thích về mục đích và nội dung của nghiên cứu trước khi tiến hành phỏng vấn và chỉ tiến hành khi có sự chấp nhận hợp tác tham gia của đối tượng nghiên cứu. Mọi thồng tin cá nhân về đối tượng nghiên cứu được giữ kín. Các số liệu, thông tin thu thập được chỉ phục vụ cho mục đích nghiên cứu, không phục vụ cho mục đích nào khác.

\section{KẾT QUẢ NGHIÊN CỨU}

3.1. Mô tả kiến thức về chăm sóc sức khỏe thời kỳ hậu sản của các bà mẹ tại khoa sản Bệnh viện Đa Khoa Vinmec

Bảng 3.1 Đặc điểm chung của đôî tượng nghiên cứu $(n=201)$

\begin{tabular}{|c|c|c|c|}
\hline \multicolumn{2}{|c|}{ Dặc điếm } & Số lượng & Tỷ lệ (\%) \\
\hline \multirow{2}{*}{$\begin{array}{c}\text { Nhóm } \\
\text { tuối }\end{array}$} & $\leq 20$ tuối & 3 & 1,5 \\
\cline { 2 - 4 } & $20-30$ tuối & 128 & 63,7 \\
\hline \multicolumn{2}{|c|}{ Tuối trung bình } & 70 & 34,8 \\
\hline \multirow{2}{*}{$\begin{array}{c}\text { Nghề } \\
\text { nghiệp }\end{array}$} & $\begin{array}{c}\text { Nông dân, } \\
\text { công nhân }\end{array}$ & 9 & $4,6 \pm 4,0$ năm $(19-42)$ \\
\cline { 2 - 4 } & Nội trợ & 19 & 9,5 \\
\cline { 2 - 4 } & Cán bộ, & 118 & 58,7 \\
\hline
\end{tabular}




\begin{tabular}{|c|c|c|c|}
\hline & viên chức & & \\
\hline & $\begin{array}{l}\text { Học sinh, } \\
\text { sinh viên }\end{array}$ & 17 & 8,4 \\
\hline & Kinh doanh & 38 & 18,9 \\
\hline \multirow{4}{*}{$\begin{array}{l}\text { Trình độ } \\
\text { học vấn }\end{array}$} & $\begin{array}{c}\text { THCS trở } \\
\text { xuống }\end{array}$ & 7 & 3,5 \\
\hline & THPT & 16 & 7,9 \\
\hline & $\mathrm{CĐ}, \mathrm{\oplus H}$ & 162 & 80,6 \\
\hline & Sau ĐH & 16 & 7,9 \\
\hline \multirow{2}{*}{ Nơi sống } & Nông thôn & 51 & 25,4 \\
\hline & Thành thị & 150 & 74,6 \\
\hline
\end{tabular}

Nhânn xét: - Độ tuối trung bình của đối tượng nghiên cứu là 29,6 thấp nhất là 19 và cao nhất 42 tuổi.

- Trong số các bà mẹ được phỏng vấn, nhóm bà mẹ từ 20-30 tuổi chiếm tỷ lệ cao nhất $(63,7 \%)$, thấp nhất là nhóm bà mẹ dưới 20 tuổi (1,5\%).

- Phần lớn các bà mẹ là cán bộ viên chức chiếm tỷ lệ 58,7\%.

- Các bà mẹ có trình độ cao đẳng, đại học chiếm tỷ lệ cao nhất $(80,6 \%)$ trong khi bà mẹ có trình độ THCS trở xuống chiếm tỷ lệ rất thấp 3,5\%.

- Trong số các đối tượng NC thì có $74,6 \%$ bà mẹ sống ở thành thị và $25,4 \%$ bà mẹ sống ở nông thôn.

Bảng 3.2. Tỷ lệ giữa các bà mẹ vê số con (n=321)

\begin{tabular}{|c|c|c|}
\hline Số lần sinh & Số đối tượng & Tỷ lệ \% \\
\hline 1 lần & 122 & 60,7 \\
\hline Trên 1 lần & 79 & 39,3 \\
\hline
\end{tabular}

Nhân xét: Đa số các bà mẹ sinh con lân đâu $(60,7 \%)$, sau đó là đến bà mẹ sinh con từ 2 lần trở lên.

Bảng 3.3. Bảng phân bố phân trăm kiên thức thời kỷ hậu sán của bà mẹ

\begin{tabular}{|c|c|c|c|c|}
\hline \multirow{2}{*}{ Đắc điểm } & \multicolumn{2}{|c|}{ Đạt } & \multicolumn{2}{c|}{ Chưa đạt } \\
\cline { 2 - 5 } & $\begin{array}{c}\text { Số } \\
\text { lượng }\end{array}$ & $\begin{array}{c}\text { Tỹ lệ } \\
\text { \% }\end{array}$ & $\begin{array}{c}\text { Số } \\
\text { lượng }\end{array}$ & $\begin{array}{c}\text { Tỹ lệ } \\
\text { \% }\end{array}$ \\
\hline $\begin{array}{c}\text { Kiến thức chăm sóc } \\
\text { sức khỏe bà mẹ }\end{array}$ & 162 & 80,6 & 39 & 19,4 \\
\hline $\begin{array}{c}\text { Kiến thức chăm } \\
\text { sóc sức khỏe trẻ } \\
\text { sơ sinh }\end{array}$ & 195 & 97,1 & 6 & 3,0 \\
\hline
\end{tabular}

Nhân xét: Theo tác giả, nếu bà mẹ trả lời đúng từ $50 \%$ trở lên được cho là có kiến thức đạt để chăm sóc sức khỏe bà mẹ và trẻ sơ sinh thời kỳ hậu sản (bao gồm dấu hiệu xuống sữa, nhận biết dấu hiệu nguy hiểm, cách phòng ngừa nhiễm khuẩn hậu sản, thời gian bắt đâuu quan hệ tình dục, dinh dưỡng và các biện pháp tránh thai).

Bảng 3.3 cho thấy có $80,6 \%$ bà mẹ đạt đủ kiến thức về chăm sóc sức khỏe thời kỳ hậu sản và $97,1 \%$ có kiến thức đạt về chăm sóc trẻ sơ sinh (bao gồm giữ ấm cho trẻ, vệ sinh cho trẻ, nuôi con bằng sữa mẹ, tiêm chủng cho trẻ sơ sinh).

Bảng 3.4. Môi liên quan giữa kiến thức chăm sóc sức khỏe bà mẹ thời kỳ hậu sán và một số yếu tố

\begin{tabular}{|c|c|c|c|c|}
\hline \multirow{2}{*}{ Đặc điểm } & \multicolumn{2}{|c|}{ Đạt } & \multirow{2}{*}{$\begin{array}{c}\text { OR } \\
(95 \% \mathrm{CI})\end{array}$} & \multirow[b]{2}{*}{$\mathbf{p}$} \\
\hline & SL & $\%$ & & \\
\hline \multicolumn{3}{|c|}{ Nhóm tuối } & & \\
\hline$<20$ tuối & 2 & 66,7 & 1 & - \\
\hline 20-30 tuổi & 104 & 82,3 & $\begin{array}{c}2,2 \\
(0,2-25,2)\end{array}$ & $>0.05$ \\
\hline >30 tuổi & 56 & 80 & $\begin{array}{c}2,0 \\
(0,2-24,2)\end{array}$ & $>0,05$ \\
\hline \multicolumn{3}{|c|}{ Nơi sống } & & \\
\hline Thành thị & 45 & 88,2 & 1 & - \\
\hline Nông thôn & 117 & 78 & $\begin{array}{c}0,5 \\
(0,2-1,2)\end{array}$ & $>0,05$ \\
\hline \multicolumn{3}{|c|}{ Trình độ học vấn } & & \\
\hline $\begin{array}{l}\text { THCS trở } \\
\text { xuống }\end{array}$ & 5 & 71,4 & 1 & - \\
\hline THPT & 11 & 68,8 & $\begin{array}{c}0,9 \\
(0,1-6,5) \\
\end{array}$ & $>0,05$ \\
\hline $\mathrm{C} \oplus, \mathrm{DH}$ & 131 & 80.9 & $\begin{array}{c}1,7 \\
(0,3-9,2)\end{array}$ & $>0,05$ \\
\hline Sau $Đ H$ & 15 & 93,8 & $\begin{array}{c}6,0 \\
(0,4-9,4)\end{array}$ & $>0,05$ \\
\hline \multicolumn{3}{|c|}{ Nghề nghiệp } & & \\
\hline Nông dân & 1 & 11,1 & 1 & - \\
\hline Nội trợ & 13 & 68,4 & $\begin{array}{c}1,7 \\
(5,5-11,8)\end{array}$ & $>0,05$ \\
\hline $\begin{array}{l}\text { Cán bộ, } \\
\text { Công chức }\end{array}$ & 107 & 90,7 & $\begin{array}{c}7,8 \\
(5,4-11,2)\end{array}$ & $\begin{array}{c}0,000 \\
1\end{array}$ \\
\hline $\begin{array}{l}\text { Học sinh, } \\
\text { sinh viên }\end{array}$ & 10 & 58,8 & $\begin{array}{c}1,1 \\
(0,8-15,8)\end{array}$ & 0,02 \\
\hline Kinh doanh & 31 & 81,6 & $\begin{array}{c}3,5 \\
(2,1-5,9)\end{array}$ & $\begin{array}{c}0,000 \\
1\end{array}$ \\
\hline \multicolumn{5}{|c|}{ Số lần sinh con } \\
\hline 01 lân & 97 & 79,5 & $\frac{1}{1-3}$ & - \\
\hline Trên 01 lần & 65 & 82,3 & $\begin{array}{c}1,2 \\
(0,6-2,5)\end{array}$ & $>0,05$ \\
\hline
\end{tabular}

Nhận xét: - Các bà mẹ có nhiều tuổi hơn thì có kiến thức tốt hơn, bà mẹ trên 20 tuổi có kiến thức đạt cao gấp hơn 2 lần bà mẹ dưới 20 tuổi.

- Những bà mẹ sống ở thành thị có kiến thức tốt hơn các bà mẹ sống ở nông thôn.

- Những bà mẹ có trình độ học vấn càng cao thì có tỷ lệ kiến thức đạt càng cao, đặc biệt nhóm trình độ học vấn sau $\mathrm{OH}$ có kiến thức đạt cao gấp 6 lần nhóm trình độ học vấn từ THCS trở xuống.

- Các bà me sinh con lần thứ 2 trở đi có kiến thức tốt hơn gấp 1,2 lần các bà mẹ sinh con lần đầu, tuy nhiên các mối liên quan này chưa có ý nghĩa thống kê với p>0,05.

- Nhóm nghề nghiệp khác nhau thì có mức độ hiểu biết khác nhau, những người làm công việc cán bộ, công chức có tỷ lệ kiến thức đạt cao gẩp 
7,8 lần người nông dân, mối liên quan có ý nghĩa tống kê $(95 \% \mathrm{CI}=5,4-11,2, \mathrm{p}<0,05)$.

\section{BÀN LUÂN}

Trong thời kỳ hậu sản, phụ nữ có những thay đổi về tâm sinh lý, có thể tác động tiêu cực đến chất lượng cuộc sống. Kiến thức của phụ nữ về các biến chứng sau sinh và cách chăm sóc có thể giúp họ vượt qua giai đoạn quan trọng này thành công. Nghiên cứu này được thực hiện trên 200 phụ sản tại khoa phụ sản của bệnh viện đa khoa Vinmec năm 2021. Dựa trên kết quả nghiên cứu, tuổi trung bình của các bà mẹ là 29,60 $\pm 4,0$ tuổi. Đa số đối tượng là cán bộ, viên chức $(58,7 \%)$ có trình độ học vấn từ cao đẳng, đại học trở lên $(88,5 \%)$. Ngoài ra, khu vực sống của các đối tượng chủ yếu là ở thành thị $(74,6 \%)$, là người dân tộc kinh (93\%) và không theo tôn giáo $(73,1 \%)$. Theo kết quả, $60,7 \%$ bà me sinh con lần đầu. Hầu hết các bà mẹ có tìm hiểu kiến thức sau sinh $(99 \%)$ từ nhiều nguồn khác nhau đa số là internet. Các kết quả này cao hơn kết quả nghiên cứu của tác giả Vũ Đình Hùng (2018) [3].

Trong nghiên cứu này cho thây có $80,6 \%$ bà mẹ đạt đủ kiến thức về chăm sóc sức khỏe thời kỳ hậu sản và $97,1 \%$ có kiến thức đạt về chăm sóc trẻ sơ sinh. Sở dĩ có sự khác nhau này là do các bà mẹ có xu hướng quan tâm đến sức khoẻ của con hơn bản thân. Kết quả này cũng tương đương với kết quả của tác giả Bùi Minh Tiến khi nghiên cứu tại bệnh viện phụ sản Thái Bình $(81,2 \%)$ [4] và cao hơn kết quả nghiên cứu tại Thanh Hoá năm 2016 (31,9\%) [5]. Điều này cho thấy sự phát triển của công nghệ thông tin giúp cho các bà mẹ dễ dàng tiếp cận kiến thức. Ngoài ra cho thấy hiệu quả của việc cung cấp kiến thức cho các bà mẹ qua các lớp học tiền sản của bệnh viện.

Kết quả nghiên cứu tìm thấy mối liên quan có ý nghĩa thống kê giữa kiến thức chăm sóc sức khoẻ thời kỳ hậu sản của bà me và yếu tố nghề nghiệp. Cụ thể trong nghiên cứu này các bà mẹ là cán bộ, công chức thì có tỷ lệ kiến thức đạt xao nhất và cao gấp 7,8 lần so với các bà mẹ là nông dân với $p<0,05$. Ngoài ra các bà mẹ đa số nằm trong độ tuổi 20 đến 30 tuổi, sinh con lần đầu thì có kiến thức tốt hơn gấp 2 lần so với các bà me có độ tuổi dưới 20 . Điều này phù hợp với đặc điểm nhân khẩu học của nghiên cứu khi có tới $63,7 \%$ người tham gia nghiên cứu có độ tuổi từ 20 đến 30 tuổi đồng thời đây cũng là độ tuổi các bà me có kiến thức tốt, có nhiều mối quan tâm đến sức khoẻ sinh sản. Những bà me sống ở nông thôn có tỷ lệ kiến thức đạt thấp hớn so với những bà mẹ sống ở thành thị. Những người phụ nữ ở thành thị dễ dàng tiếp cận với các dịch vụ chăm sóc sức khoẻ sinh sản và các thông tin tư vấn của các nhân viên y tế. Các bà me có trình độ học vấn cao đẳng, đại học và sau đại học thì có kiến thức đầy đủ và tốt hơn. Có sự liên quan giữa số lần sinh con và thưc hành chămm sóc sau sinh của bà mẹ, bà me sinh từ hai lần trở lên có cơ hội thực hành cao từ đó có kiến thức tốt hơn bà mẹ sinh con lần đầu.

Trong nghiên cứu này còn hạn chế với cõ̃ mẫu $\mathrm{N}=201$ tương đối nhỏ, vì thế kết quả nghiên cứu chỉ áp dụng với bệnh viện đa khoa Vinmec chứ không có tác dụng ngoại suy ra các quần thể khác. Cần có các nghiên cứu với cỡ mẫu lớn để đánh giá một cách toàn diện hơn về kiến thức của các bà me về chăm sóc sức khoẻ thời kỳ hậu sản.

\section{KẾT LUẬN VÀ KIẾN NGH!}

Nghiên cứu 201 đối tượng là bà me sau sinh tại khoa Phụ sản, bệnh viện đa khoa Vinmec cho thấy có $80,6 \%$ bà me có đạt kiến thức về chăm sóc sức khoẻ sau sinh và $97,1 \%$ bà me đạt kiến thức chăm sóc sức khoẻ sau sinh. Nghiển cứu tìm ra mối liên quan có ý nghĩa thống kê giữa yếu tố nghề nghiệp và kiến thức về chăm sóc sức khoẻ thời kỳ hậu sản. Nghiên cứu hiện tại chưa tìm ra mối liên quan có ý nghĩa thống kê với các yếu tố nhân trắc học khác.

Từ các kết quả của nghiên cứu, chung tôi đưa ra một số khuyến nghị sau đây:

- Cần tăng cường, duy trì tổ chức các lớp học tiền sản, các buổi truyền thông giáo dục sức khoẻ nhằm nâng cao kiến thức, đặc biệt đối với các bà me ở khu vực nông thôn.

- Đẩy mạnh phát triển các tài liệu trực quan: video, hình ảnh.giúp khách hàng dễ dàng hiểu và vận dụng tốt hơn kiến thức vào thực hành theo dõi và chăm sóc hậu sản.

\section{TÀI LIẸU THAM KHẢO}

1. Chăm sóc phụ nữ thời kì hậu sản. YouMed <https://youmed.vn/tin-tuc/cham-soc-phu-nu-thoiki-hau-san/>

2. GSTS. Nguyễn Đức Vy (2006). Bài giảng sản phụ khoa (sách dùng cho sau đại học). Nhà xuất bản Y học Hà Nội,

3. Vũ Đình Hùng (2018)- Kiến thức thời kỳ hâuu sản và chăm sóc hậu sản của sản phụ sau sinh nằm tại khoa phụ sản bệnh viện Bạch Mai 2016,

4. Bùi Minh Tiến (2021)- Một số yếu tố liên quan đến kiến thức chăm sóc saú sinh của bà me sinh con lần đâu tại bệnh viện Phụ sản Thái Bình. <https://tapchiyhocvietnam.vn/index.php/vmj/artic le/view/397/289>, accessed: 07/12/2021.

5. Thực trang kiến thức, thực hành chăm sóc sau sinh̆ ở bà me có con dưới 1 tưổi" tại 3 xã bãi ngang huyện Hậu Lộc, Thanh Hóa năm 2016. 